\title{
Design and Development of Health Monitored Quick Appointment System
}

\author{
Lincon Ahuja \\ Academic Consultancy Service Division \\ Center for Advance Computing \\ Mohali, India
}

\author{
Prashant Bhardwaj \\ ACSD Dept. \\ Center for Advance Computing \\ Mohali, India
}

\begin{abstract}
As the population is increasing worldwide, a huge need arises to provide proper health-care services. India is such a country, where the population keeps on rising every year and the government is not able to provide basic health care check-ups due to lack of a number of doctors in the country. The research focuses on measuring basic health parameters like pulse rate and body temperature using a microcontroller and develop an android app for appointment of doctor. In conventional system, patients have to physically wait in queues in order to get the appointment. The main objective of this paper is to reduce the time for the appointment and to increase the number of patients per day by doctor, as we know doctors per 1000 person is 0.7. In our developed system, we have used microcontroller for interfacing pulse rate sensor and temperature sensor. On the other side, we have developed an android application, in which patient will fill his/her details and all data will be stored which we can access later on .These health monitored data is displayed on doctor's application.
\end{abstract}

\section{Keywords}

Pulse Rate Sensor, Temperature Sensor, PIC Microcontroller, Android App.

\section{INTRODUCTION}

Due to rise in population, the demand to provide proper health care services has increased to a new level. India ranks second in terms of population, where it keeps on rising every year and the government is not able to provide basic health care checkups due to lack of a number of doctors in the country. There is one doctor per 1700 people in India as against the WHO limit of ratio 1:1000. People suffer a lot due to long standing queues in government hospitals. Healthcare needs are wielding enormous strain on the dainty health care delivery system. Besides, negative factors like shortages of staff, work overload and low allocation of health care budgets have bothered the health care system. Thus, economical, social, and demographic trends need to provide efficient health will provide solutions to the quality of life of the people who use technical leadership. According to the health ministry, there are around six to seven lakh doctors, but still it does fulfill the need of the country. We would around need more four lakh doctors to meet the WHO limits by 2020 . This shows the dark side of poor service quality. Sixty years ago the total number of physicians was 47,524 , with doctor population ratio of 1 to 6300 . Today, the number of registered medical practitioners is 840,130 (a 17 fold increase). Another way to add sugar into it, is using technology in healthcare. Like using smart phone for learning, booking slots for appointment and using instruments for measuring health parameters e.g.: Heart rate, body temperature and blood pressure etc..
Mobile healthcare monitoring systems are very popular these days because of their fast delivery, data storage and self management of daily activities. For example, fitness bands which stack up the health parameters, calories burnt and so on android app, are helpful in managing health of an individual [1].

\section{RELATED WORK}

While surveying we concluded that a system is designed by Amir Hoshang Kioumars et al.[2] for collection of real time human body vitals such as body temperature, heart rate is very vital. To accomplish this task, a controller can be configured such that it transmits the sensed data to a remote PC station using wireless technology. Zigbee technology is preferred because it aids in reducing the power consumption of the overall system. The sensor would be wrapped around the wrist of the subject person and the measured data would be displayed on the LCD display on the remote PC station using the Xbee module.

In this reseach work Prof. S. B. Choudhar et al.[3] has designed an android application, in which resigtered patient will get the appointment within next $24 \mathrm{hrs}$ and the unregidtered one will in next 24 to $48 \mathrm{hrs}$. Senior citizens are given priority and can fix with in 2 to $4 \mathrm{hrs}$. In case of deadlock of two patients, patient who has applied earlier will be preference.

So-Youn Park et al. [4] designed a system for diagnosing diseases. A piezoelectric film sensor was used. This device gave the information of heart and liver illness disorder. The working of the system was in three steps as in the first step a pulse detection sensor got pulse signals from patient's wrist at measuring point. The signals of sensor ware extremely weak and have impurities like noise was there, so the need of an amplifier and filter was there. In second step, the conversion of pulse signal from an analog signal to digital signal was required which was obtained from an analog circuit to identify

Various work is also done in the android field Deepa V. Jose et al.[5]. Discussed various challenges and issues before designing an Android app.Tthe programming language used is Java, the platform is Eclipse, Android ADT and the Android SDK are used. Android System is a Linux-based system and its architecture comprise of four layers. The first is Linux Kernel which is Android inner nuclear layer to perform operations such as bottom drive, internal storage etc. The second is Libraries and Android runtime which consists of Java core libraries and Dalvik Virtual Machine. It also supports application framework. These libraries are written in $\mathrm{C} / \mathrm{C}++$. The third layer is Application Network, which makes all API network accessible for key programs. The fourth layer is Application which is a group of many applications like browser, home, contacts etc. Much testing is done for this mobile application PikDish. One of the test was 
done in three environments, namely hardware, software and network, which showed good performance of audio and video player and reduced advertisement.

\section{PROPOSED WORK}

India is such a country, where the population keeps on rising every year and the government is not able to provide basic health care checkups due to lack of a number of doctors in the country. In India doctors per 1000 people is 0.7[1]. People suffer a lot due to a large number of lines in government hospitals. So, I have designed a health monitoring system along with appointment system. In this system, the health sensing device will collect the health monitored parameters and will display on the LCD. Then, the patient will fill all his details on android app and fill the data from the health monitored device, transmit data to the cloud and get quick appoint. With this, patient doesn't have to wait in queues. These parameters check-up takes at least 2 to 3 minutes and by this doctor checking-ups of patients in a single day decreases by $20 \%$. In earlier papers, the researchers have used temperature sensor and pulse rate using Arduino and have transmitted data to through Zigbee[2]. Because they have used Arduino that does not make it cost effective and portable. As in this research work one IR sensor and one temperature sensor interfaced with PIC microcontroller along with an android app, which will schedule the appointment to the patient.This proposed work provide significance as, Using online scheduling it lesser the pain of the patient for booing appointment slot. This also saves monetary expenses of the staff paper work. This system also helps to check basic health parameter of patient on a daily basis.

\section{HARDWARE DESCRIPTION}

Fig.1 shows the block diagram of the proposed work Consist of various hardware modules such as Pulse rate sensor, temperature sensor, LCD display, PIC microcontroller, android app.

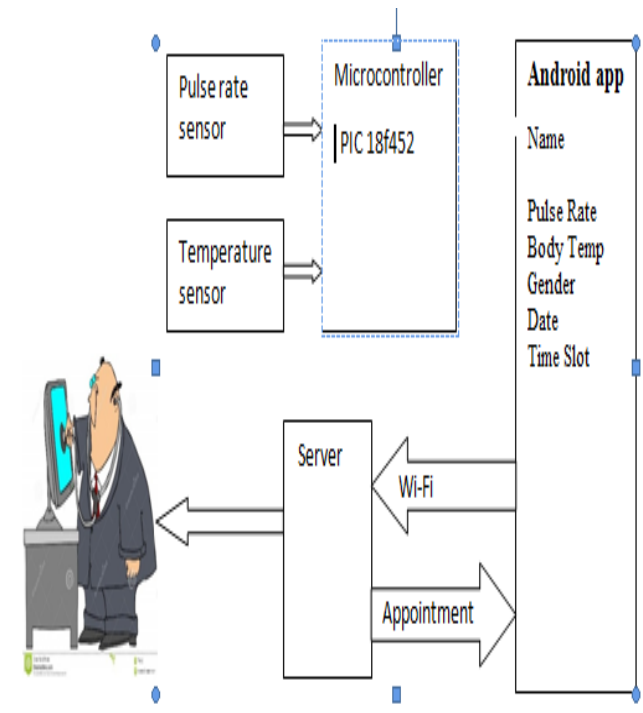

Fig 1: Block diagram of proposed system

\subsection{Microcontroller}

PIC18F452 microcontroller is used in this proposed work. Microcontroller has analyzed the ADC data and send the data and commands to the LCD to display heart rate and pulse rate on the LCD.

\subsection{Sensors}

Two sensors are used in this health monitoring system one is pulse rate sensor and other is temperature sensor.

A pulse rate sensor is used in order to check the heart rate of patient as a clinical data by using TCRT 1000 sensor. This sensor is based on IR technology. IR (TRCT1000) sensors are used in this thesis work for detecting the pulses of at the tip of the finger. It is a reflective type IR sensor which is working on 950nm range of light. IR detector is also inbuilt in this IR sensor. It provides fluctuation of pulses in MV range[4].

The second parameter that we have calculated is body temperature by using a 10k NTC thermistor. This works with a principal of temperature and resistance relationship. The thermostat that we have used in our work is NTC (negative temperature coefficient) means an increasing resistance temperature decreases and vice versa.

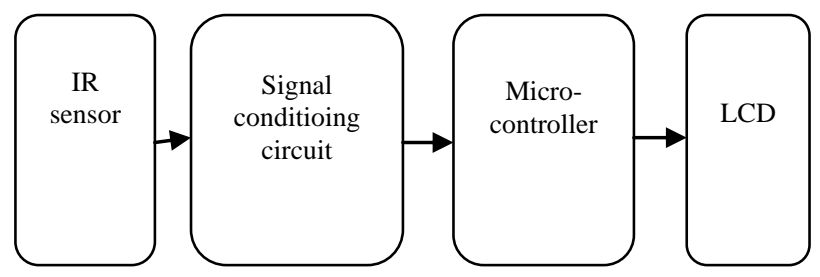

Fig 2: Pulse reader system

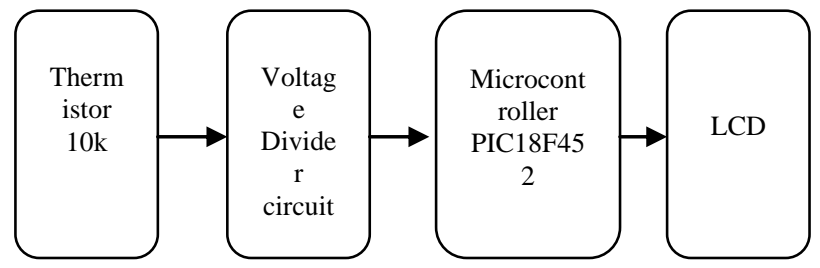

Fig 3: Temperature reader system

\subsection{Android Aplication}

This whole system is based on networking. In this part the data collected from hardware part is is displayed on LCD. So, that the patient (in digital world patient is called as virtual patient). This outcome of pulse rate and body temperatrure entered into android application. Furhter, patient will select the date for the appointment and enter the details like name, gender, age, email id, pulse rate, temperature and select the time for the appointment as given the slots. It will not the show the time which is fixed earlier by an other patient. These all details will be stored on the other side in database to the server.

The connectivity of android application done in php. Here, first of all http post is used to get to data sending the details and convert these response to string parsa JSON data and Mysql software is used for database. The designing and shaping of buttons, text, coloums is done in .xml. The size setting length, height, width, shape of the buttons is done by using .xml and these buttons performs activies and for that .java file is created[6].

Another login in this application is for the doctor, where he can check his appointments and details of the patients on the date and time of appointment basis. A wireless Machine to Machine communication is done by IPv4 technology for healthcare solution of the patient. The M2M devices are smart phone and computer (which acts as a server) and used for the transmitting information about the patient to serve through IP enabled internet and visualization of patient information on 
android application. These medical systems design focuses on two different systems within a system one of sensing, health parameters by designing an embedded system and another one designing android app for putting all physiological parameters and personal details of patients. This work presents web based real time monitoring of body temperature sensor and pulse rate sensor along with designing real time android app. This application can run on Android version which comes after Froyo. In the below flow diagram methology of the android applicaton is explained.

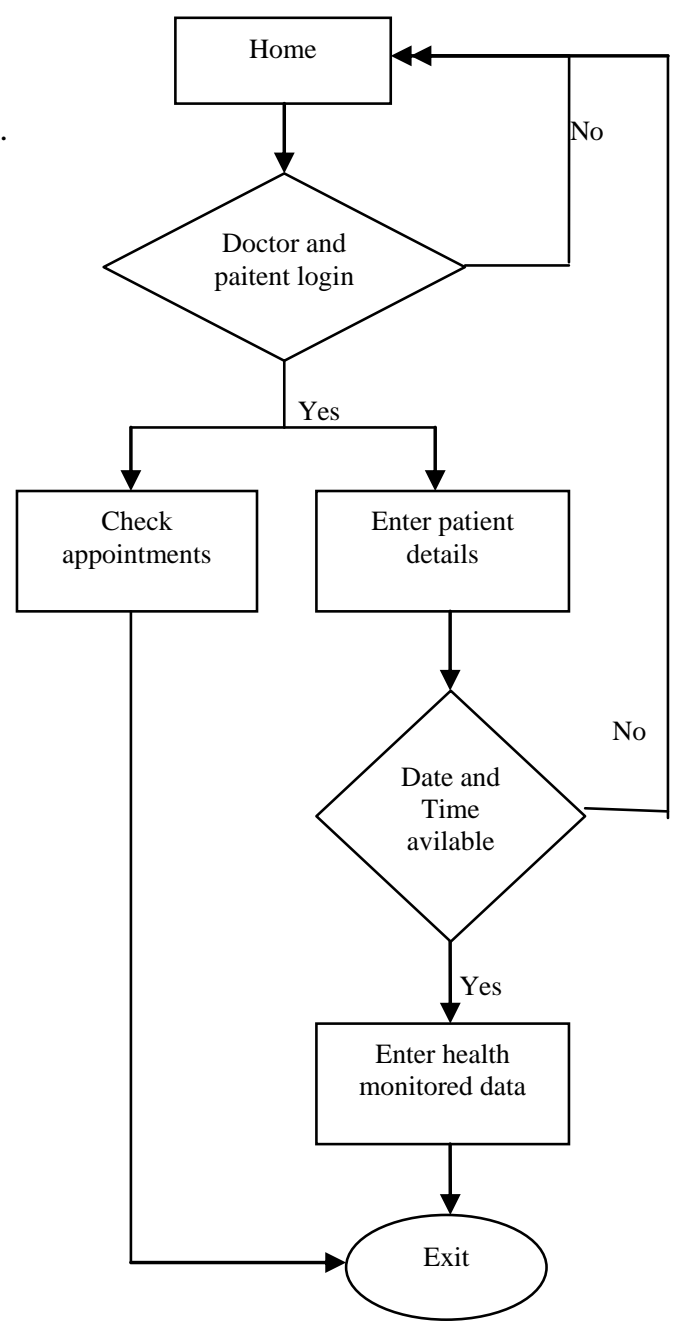

Fig 4: Block diagram of proposed work

\section{SOFTWARE DESCRIPTION}

In purposed system, software part is divided in two parts. The first one is for interfacing pulse rate sensor and temperature sensor. In this part programming for the sensors is done in MP lab. System c is used for programming. And the second part of programming for development of an android application. For that android studio is used for java programming and Mysql for database.

\subsection{Pulse Reader System Methodology}

This system programming is done in c language in Mplab software. In this system, the microcontroller will first initialize the timer and wait for $6 \mathrm{Sec}$. Then, the timer will count the timer to count the pulses. After that controller will calculate the pulses per minute. This data send to LCD for display. To get the accuracy of pulse rate system filter circuit is used and after that an amplifier circuit, which will amplify to required value so that it can display correct reading. In this system TCRT 1000 is used that is based on IR sensor technology. The sensor will transmit the signal into blood vain and receive. As the heart pumps in and out, the stream of the blood would be accordingly. By this method TCRT sensor will get to know about pulse rate or heart rate in the human body.

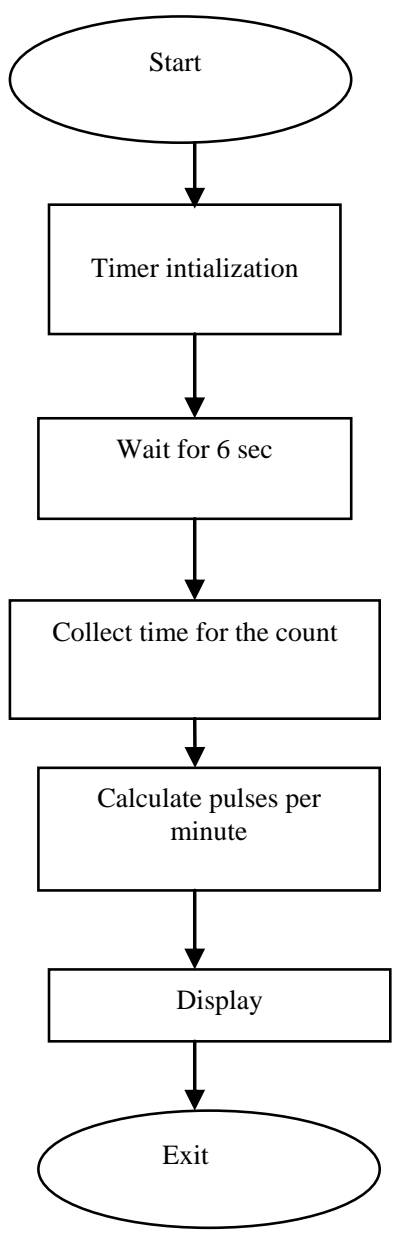

Fig 5: Flow diagram of pulse reader system

\subsection{Temperature Reader System Methodology}

The designed system coding is done in Mplab. Initially controller will initialize the ADC to convert the analog value to digital. After completion of the conversion all the data into digital data is collected. Then the data is displayed on the LCD. 


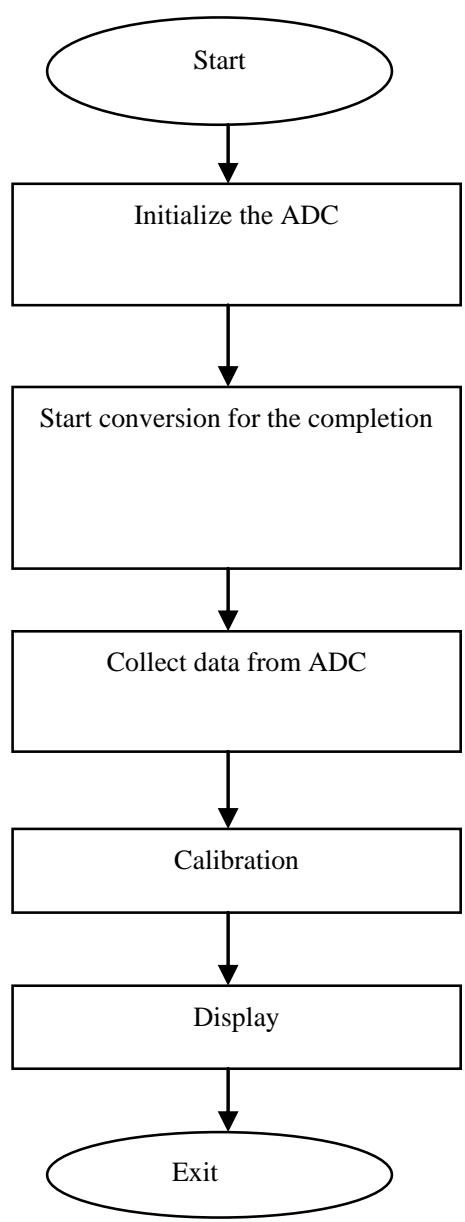

Fig 6: Flow diagram of body temperature system

\section{RESULT AND ANALYSIS}

\subsection{Results of Health Monitered System}

This system gives results on the LCD in numeric form. Designed system shows pulse rate and temperature.It also shows the improvement, health care appointment system and reduces time to take the appointment. This increases the efficiency of the doctor in treating a number of patients in a day. Initially designed system shows room temperature, after attaching system to the patient's finger tip, it shows body temperature and pulse rate or heart rate. The result given below shows the result of a person whose age is 20 years in figure 1 .

Table 1. Readings of Health Monitoring System

\begin{tabular}{|c|c|c|c|}
\hline $\begin{array}{c}\text { Name of the } \\
\text { person }\end{array}$ & Age & $\begin{array}{c}\text { Reading of } \\
\text { pulse rate }\end{array}$ & $\begin{array}{c}\text { Expected } \\
\text { Reading of } \\
\text { pulse rate }\end{array}$ \\
\hline P1 & 24 & 83 & 89 \\
\hline P2 & 27 & 85 & 90 \\
\hline P3 & 28 & 88 & 95 \\
\hline P4 & 15 & 70 & 74 \\
\hline P5 & 28 & 88 & 90 \\
\hline
\end{tabular}

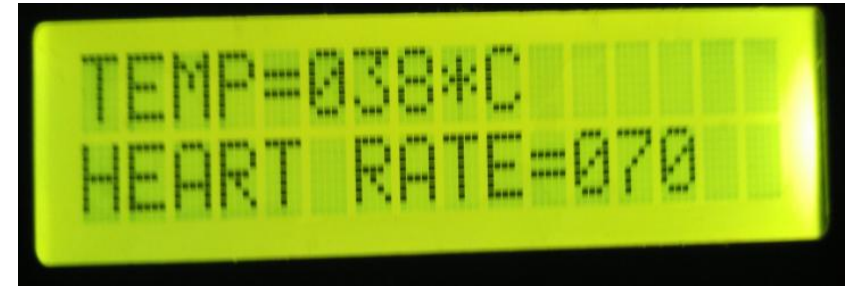

Fig 7: Measured value of heart rate and body temperature

Table 2. Results of the system

\begin{tabular}{|c|c|c|}
\hline Function & $\begin{array}{l}\text { System without } \\
\text { using android app }\end{array}$ & $\begin{array}{l}\text { System using } \\
\text { android app }\end{array}$ \\
\hline $\begin{array}{l}\text { Appoint- } \\
\text { ment } \\
\text { System }\end{array}$ & $\begin{array}{l}\text { Have to stand in } \\
\text { queues or have to } \\
\text { book through phone }\end{array}$ & $\begin{array}{l}\text { No need to } \\
\text { stand in } \\
\text { queues, user } \\
\text { can directly } \\
\text { book the } \\
\text { appointment } \\
\text { sitting at } \\
\text { home }\end{array}$ \\
\hline $\begin{array}{l}\text { Time to } \\
\text { check } \\
\text { clinical } \\
\text { data }\end{array}$ & $\begin{array}{c}\text { Usually doctor takes } 5 \\
\text { to } 6 \text { minutes to check } \\
\text { pulse rate and } \\
\text { temperature }\end{array}$ & $\begin{array}{l}\text { Clinical data } \\
\text { is already } \\
\text { present at the } \\
\text { doctor's cabin } \\
\text { and saves this } \\
\text { time }\end{array}$ \\
\hline $\begin{array}{c}\text { No. of } \\
\text { patients }\end{array}$ & $\begin{array}{c}\text { The Doctor takes total } \\
\text { average } 10-12 \text { min to } \\
\text { a patient }\end{array}$ & $\begin{array}{l}\text { Using this } \\
\text { doctor will take } \\
\text { total average } \\
\text { time } 6-7 \\
\text { minutes }\end{array}$ \\
\hline $\begin{array}{l}\text { Effici- } \\
\text { ency }\end{array}$ & $\begin{array}{c}\text { No of patients in } 1 \\
\text { hour }=6\end{array}$ & $\begin{array}{c}\text { No. Of } \\
\text { patients in } 1 \\
\text { hour }=10\end{array}$ \\
\hline
\end{tabular}

This app is for fixing the appointment with the doctor of the hospital. In this android application user can select the hospital in which he wants to get an appointment. A person can also select a department, after that he/she canbook the time slot which is available.

\subsection{Android App}

This page shows the login page of the android app, where the user can enter username and password. If it matches, then people would be able to book the appointment. This page is Afor filling the personal details of the patient. After filling personal details patients can go for the date and time for appointments. If slot is available, then only he can book otherwise person has to choose another slot. 


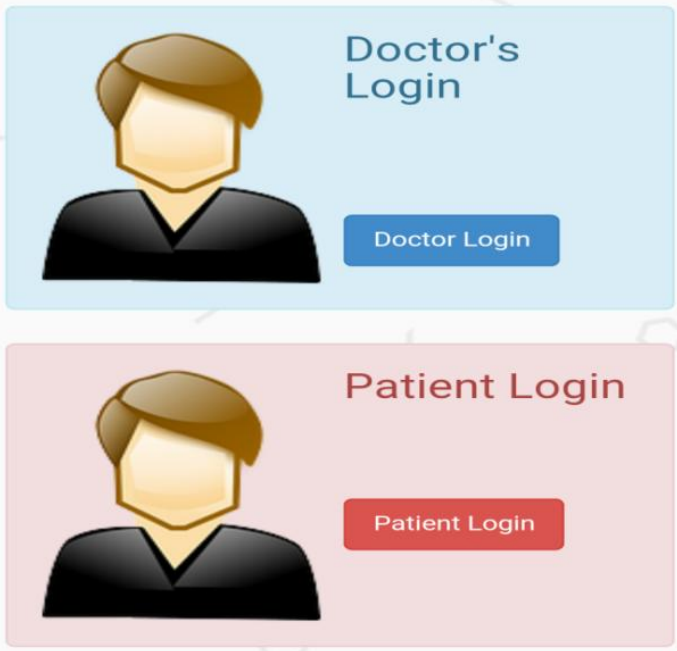

Fig 8: Login screen for doctor and patient

This page is for filling the personal details of the patient and selecting date and time slot for the appointment of doctor. In this application patient whose name is lincon as shown in the following figure have booked the 9:15 slot for the appointment as shown in the following figure 8.

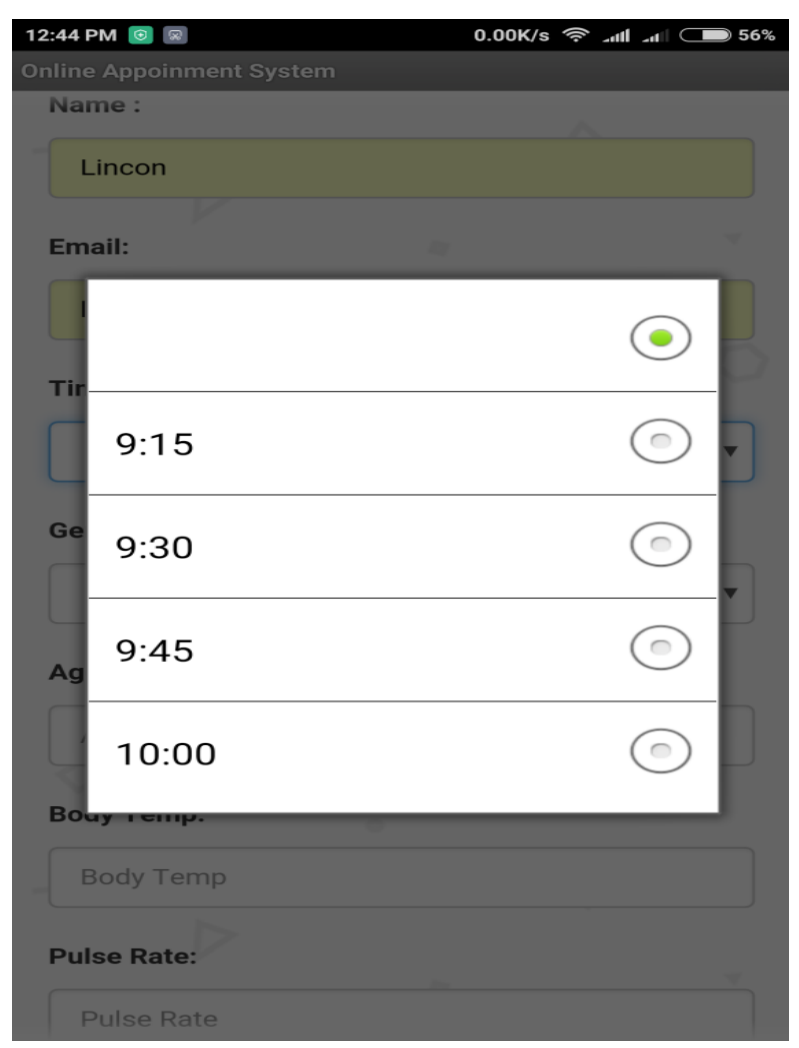

Fig 9: Booking appointment Screen
The following figure shows the final intimation for the fixing appointment on particular date and time.

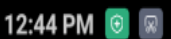

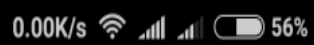

Online Appoinment System

Name: Lincon

Date: $\quad$ 2016-08-01

Time Slot: $\quad$ 9:15

Submit

Fig 10: Final submission screen

In this android application doctor will have its username and password. The figure below shows the appointment on particular day and over all appointment.

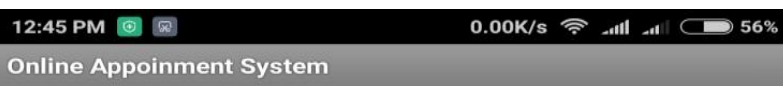
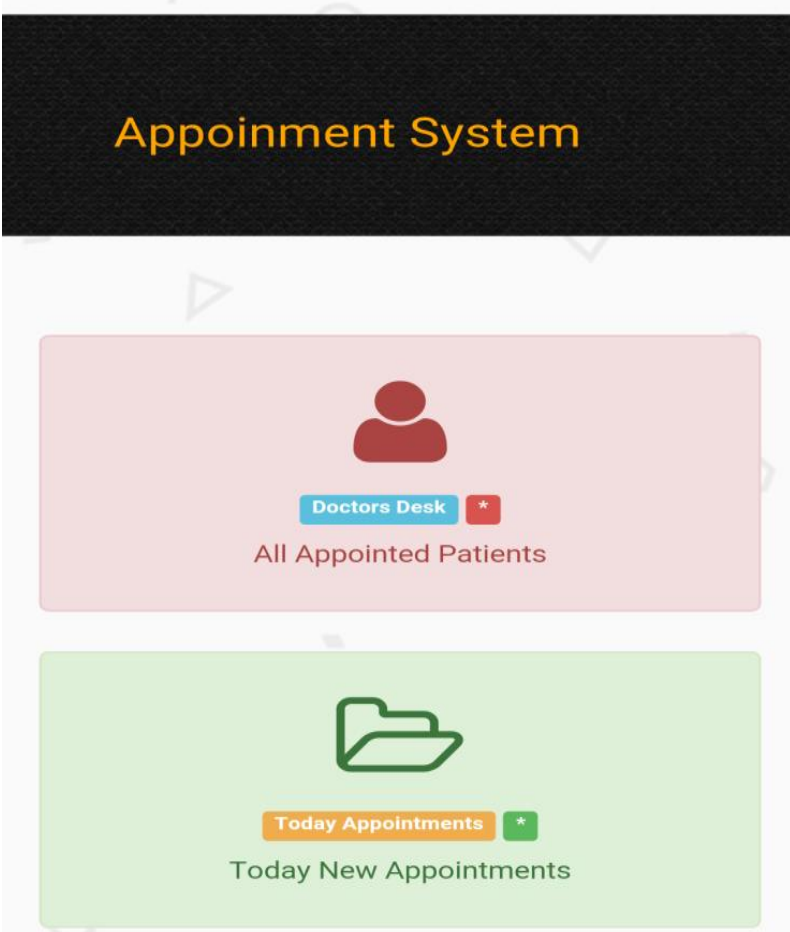

Fig 11: Doctor's appointment schedule

The figure given below mentions about the details of patients as on a particular date. As in figure patient Lincon have booked the appointment at 9:15 along with other details name, gender,age and health. 


\section{Todays Appointments}

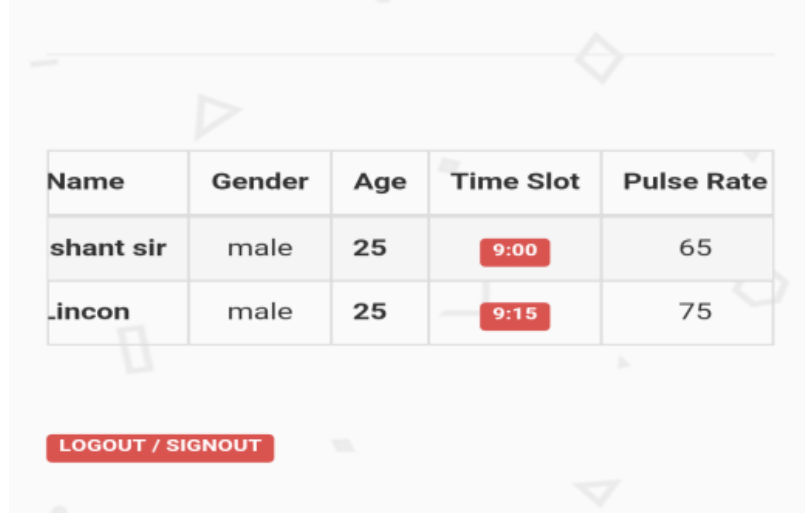

Fig 12: Patient details on doctor's app

\section{CONCLUSION AND FUTURE SCOPE}

In the conventional way patient book appointment either by physical presence over the hospital window or by using phone. Over their doctor checks basic health parameters like body temperature and heart rate. These are essential parameters which give information to doctors about the body of the patient. In this research work these health parameters are measured, So that one later on doctor can get to know about the actual situation of the patient when the patient is sick. In this thesis, temperature sensor of $10 \mathrm{k}$ thermistor is used to measure temperature of the body and pulse rate sensor TCRT 1000, which is based on the IR technology measure the heart rate to count number of pulses in a minute in other words it will check the number of times heart pumps in a minute. The reading of pulses is in the Milli volts range, so a filter circuit is designed. This provides the reading in 5 volts range. This voltage range is used by the ADC of microcontroller directly. Measurement of temperature is done by using voltage divider circuit and resistance varies according the temperature accordingly voltage changes. These sensors are interfaced with microcontroller PIC p18f452 and display the measured data on the LCD $(16 \times 2)$ in numeric. Then on the other hand, an Android application has been designed to fix the appointment with the doctor. This application will give doctors the information about the patient personal and health details. The methodology used for the temperature sensor, it will first initialize the ADC and start the conversion of the data. After conversion data is collected from ADC and calibrated. For pulse rate sensor, $\mathrm{ADC}$ received the signal from the filter circuit and calibration is done and data are displayed on the LCD. A device designed should be portable and cost effective. So this device is portable as well as portable. In this system, PIC microcontroller, thermistor of $10 \mathrm{k}$ and heart rate sensor TCRT 1000 are used which makes it cost.

\subsection{Future Scope}

In this system patient have to enter health parameter manually, but in future with the use of Bluetooth, data can be automatically transmitted to android application and can select the date and time according to their own choice. Another modification is that the system uses only two sensors for health parameter to display data in numeric on the LCD and more addition of health care parameters will help the doctor to diagnose the disease like blood pressure etc.

\section{REFERENCES}

[1] World Health Organization's Global Health Workforce Statisticsavaiableat"http://data.worldbank.org/indicator/ SH.MED.PHYS.ZS

[2] Kioumars, Amir Hoshang, and Liqiong Tang. 2011 Wireless network for health monitoring: heart rate and temperature sensor.Sensing Technology (ICST) at Fifth International Conference in IEEE.

[3] Prof. S. B. Choudhari, Chaitanya Kusurkar, Rucha Sonje 2014 "Android Application for Doctor's Appointment." International Journal of Innovative Research in Computer and Communication Engineering Vol. 2, Issue 1

[4] S.Y.Park, J.J.Lee $2007 \quad$ SelfDiagnosis Device Using Wrist Pulse in Proc. $33^{\text {rd }}$ Annual Conference of the IEEE Industrial Electronics Society(Nov. 2007) 139-142

[5] Deepa V. Jose , Lakshmi Priya C, G. Priyadarshini, M onisha Singh 2015 Challenges and Issues in Android App Development- An Overview. International Journal of Advanced Research in Computer Science and Software Engineering (January 2015)Volume 5, Issue 1

[6] Ma, Li, Lei Gu, and Jin Wang. 2014 Research and Development of Mobile Application for android Platform

[7] Data sheet of TCRT 1000 pulse rate sensor, http://www.vishay.com/docs/837 52/tcrt1000.pdf

[8] Dr.Prakash.H.Patil, Seema.V.Kamkhedkar 2014,"Wireless Machine to Machine (M2M) based eHealthcare System" in International Journal for Research in Applied Science \& Engineering Technology (IJRASET) (December 2014) Volume 2 Issue XII, 2321-9653

[9] Cerqueira Ferreira, Hiro Gabriel, Edna Dias Canedo, and Rafael T. De Sousa. 2013 IoT architecture to enable intercommunication through REST API and UPnP using IP, ZigBee and Arduino 9th International IEEE conference on Wireless and Mobile Computing, Networking and Communications (WI Mob)

[10] Patel, Maulin, and Jianfeng Wang. 2010 Applications, challenges, and prospective in emerging body area networking technologies in IEEE Wireless Communications Magazine 17.1(2010):80-88 